\title{
Preschool vision screening in Cornwall: performance indicators of community orthoptists
}

\author{
R P L Wormald
}

\begin{abstract}
The performance of community orthoptists was retrospectively assessed in a primary preschool screening programme that has been established in Cornwall since 1982. The outcome of screening was compared between random samples of two birth year cohorts corresponding to the second and fourth years of existence of the screening programme (1980, $n=298$ and 1982, $n=300$ ). The mean age at screening was significantly later for the second cohort ( 4.3 years compared with 4.4 years) but otherwise performance indicators improved in the second cohort.

Community orthoptists achieved a sensitivity of about $90 \%$ and specificity of $99 \%$ during the study. It is unlikely that the more commonly used two tier system of health visitors referring to a community orthoptist could achieve this degree of accuracy.
\end{abstract}

A preschool vision screening programme was established in Cornwall in 1982 to screen all children over 3.5 years of age living in Cornwall for visual deficit or strabismus or both. The aim of this paper was to assess the performance of the community based orthoptists who are responsible for carrying out this primary screening programme. The results of treatment of those children screened positive are presented elsewhere.

The purpose of the preschool vision screening programme is to identify children with small squints or amblyopia (or both), either strabismic or refractive, while there is still hope of treating the condition successfully, and to identify and correct any refractive error so that any visual disability is minimised before schooling begins.

It is clear from the Hall report ${ }^{1}$ and from a paper by Stewart-Brown et $a l^{2}$ that the cost effectiveness of preschool vision screening has never been proved. Many different approaches to the vision screening of children are used, and I know of little evaluation of results. Although there are a number of papers presenting the results of primary preschool vision screening by community orthoptists no formal appraisal of their performance has been published. ${ }^{3-9}$ In particular, I could find no record of any attempt to assess the sensitivity of this screening method, perhaps because of the difficulty of determining the number of children missed by screening.

With one county border and fully centralised ophthalmic and community paediatric services, Cornwall was geographically ideal for a population based analysis of the outcome of preschool vision screening.

\section{Subjects and methods}

ORGANISATION OF PRESCHOOL SCREENING

Children are identified from a computerised register into which they are entered at birth and invited to attend for screening. The register produces a printout of the names of children attaining the age of 3.5 years (when they become eligible for screening), which is sent to the screening office every few months. The register is updated by health visitors for children who enter or leave the county. The parents or guardians of eligible children are sent one invitation only for preschool vision screening, which takes place at the nearest of the 22 clinics throughout the county. Confirmation of attendance is not required, but a request is made to change or cancel the appointment if necessary.

The history and examination (which take about 10 minutes if the child is cooperative) are standard and the following are noted:

- Distance vision measured on Snellen chart at $6 \mathrm{~m}$ with card (Sheridan Gardiner chart at $6 \mathrm{~m}$ or Kay pictures are used when cooperation is poor)

- Head posture

- Convergence to nose

- Cover test, near and distance, Prism cover test: 20 dioptre base out (occasionally 10)

- Ocular movements: nine positions of gaze

- Stereoscopic vision: Wirt fly test and pictures of animals.

Criteria for referral of a child to hospital are: inability to see the 6/9 line on the Snellen chart with either eye, or inward or outward deviation on cover test ( $>8$ prism dioptres), or both. Any child with an obvious squint or other clinical abnormality is referred.

Children with detected abnormalities are referred directly to the ophthalmologist and a note is sent to the patient's general practitioner. If there is doubt about the abnormality, a follow up appointment can be made within the preschool vision screening service.

\section{METHOD OF EVALUATION}

Two birth year cohorts were selected to assess the performance of the screening programmechildren born in 1980 who are eligible for screening by mid-1983, and those born in 1982 who became eligible by mid-1985. In this way the performance during the second and fourth years of the screening programme was assessed. All children who lived in the northern and eastern ends of the county and who would normally be referred to Plymouth were excluded to facilitate retrieval of information from hospital records. Two approaches to the evaluation of outcome were made for each birth year cohort.
Institute of Ophthalmology, 27-29 Cayton Street,

Accepted 11 April 1991 
Firstly, a random sample of 300 children eligible for screening from each birth year cohort was taken directly from the computer printout used to invite children for preschool vision screening. Screening record cards for each selected child were drawn from the file and details of findings and outcome entered on to a microcomputer database.

This information allowed estimates of attendance rate, referral rate, and mean age at the time of screening for each birth year cohort.

To gain some information about why some children did not attend, a sample of nonattenders were asked questions by telephone. Records at the department of child health were scrutinised to identify the proportion of nonattenders who had changed their addresses or moved out of the county.

Secondly, another database was made from the record book at the department of child health of all the children referred from both birth year cohorts. A third database was made from a similar record of all children from the two birth year cohorts who were referred with visual abnormalities that had been detected by school medical officers soon after the children had started school; this database included the reason for referral and result of preschool vision screening.

The specificity of the primary screen by community orthoptists was calculated from the number of children referred to hospital who were found to be normal by the hospital orthoptist and consultant ophthalmologist.

The sensitivity of screening was calculated from the number of children with true abnormalities that had not been detected at the preschool vision screening (refractive error, strabisms, strabismic or refractive amblyopia) who were referred by the school medical officer. Only those children who attended preschool vision screening and who were later seen by a school medical officer were included. Nonattenders and those children who had subsequently moved into the county or who were not listed (and hence not invited to preschool vision screening) were excluded from the calculation of false negative results of preschool vision screening. Some false negative results may have been missed, because the school medical officer may also have failed to detect any abnormality. The pattern of school medical officer referral by school medical officers did if anything err on the side of caution, as there was a high false positive rate; it is unlikely, therefore, that many were missed. In addition, a number of children may have developed abnormalities between attending preschool vision screening and going to school thereby being wrongly classified as false negatives. The number of these is also likely to be small and any error arising from either of these sources will counteract itself. Finally, we calculated the predictive value of a positive screening result.

\section{Results}

RANDOM SAMPLE

The number of children sampled from each cohort was: 1980-total 4128, 298 sampled $(7 \cdot 2 \%), 145$ boys and 153 girls; and 1982 -total 3797,300 sampled $(7 \cdot 9 \%), 155$ boys and 145 girls. There was no significant difference in attendance or referral rates between the cohorts (table 1).

The mean ages at the time of screening were 4.25 years for the 1980 cohort and 4.42 years for the 1982 cohort. The probability that this difference was a chance finding as a result of a sampling error was $<0.001$ (Student's $t$ test).

Of the total sample of 598, 157 did not attend. About half the total sample were still at the same address in $1988,42 \%$ had moved ( $12 \%$ out of the county), and no information was available for $8 \%$. Only $20 \%$ of the non-attenders had telephone numbers in the local directory, which might indicate a socioeconomic influence on attendance. Of 29 phone calls made, the commonest reason for non-attendance was no recollection of receiving an appointment $(n=$ 14), followed by no appointment received ( $n=$ $6)$, already receiving treatment $(n=6)$, and already attended and screen normal $(n=3)$.

REFERRALS AFTER PRESCHOOL VISION SCREENING The actual referral rates compare well with the sample estimates of $3.7 \%$ for the 1980 cohort and $5.3 \%$ for the 1982 cohort being $3.9 \%$ and $4.6 \%$, respectively. Of the 159 referred from the first cohort there were 93 boys and 66 girls, and of the $\mathbf{1 7 6}$ referred from the second cohort there were 92 boys and 84 girls.

Table 2 lists the defects for which children were referred from both cohorts, including the false positives. Only three of the 20 squints referred by the community orthoptists from the 1980 cohort had been misdiagnosed. There were no false positive squints in the 1982 cohort.

\section{REFERRALS BY SCHOOL MEDICAL OFFICERS}

Many more children were referred by school medical officers from the 1980 cohort: 1980 , 134 and 1982, 69 (total 203). This includes all children referred by school medical officers.

Table 1 Data of each birth year cohort with $95 \%$ confidence intervals (CI)

\begin{tabular}{|c|c|c|c|c|}
\hline & \multicolumn{2}{|c|}{1980 cohort $(n=298)$} & \multicolumn{2}{|c|}{1982 cohort $(n=300)$} \\
\hline & No $(\%)$ & $95 \%$ CI of $\%$ & No $(\%)$ & $95 \%$ CI of $\%$ \\
\hline $\begin{array}{l}\text { Attenders: } \\
\text { Total No } \\
\text { No referred } \\
\text { Did not attend }\end{array}$ & $\begin{aligned} 198 & (66) \\
11 & (4) \\
82 & (28)\end{aligned}$ & $\begin{aligned} 61 & \text { to } 72 \\
2 & \text { to } 6 \\
23 & \text { to } 32\end{aligned}$ & $\begin{aligned} 204 & (68) \\
16 & (5) \\
75 & (25)\end{aligned}$ & $\begin{aligned} 63 & \text { to } 73 \\
3 & \text { to } 8 \\
20 & \text { to } 30\end{aligned}$ \\
\hline $\begin{array}{l}\text { Others: } \\
\text { Total No } \\
\text { Already being treated } \\
\text { Refused or moved away }\end{array}$ & $\begin{array}{r}18(6) \\
6(2) \\
12(4)\end{array}$ & $\begin{array}{l}3 \text { to } 9 \\
0.5 \text { to } 4 \\
2 \text { to } 7\end{array}$ & $\begin{aligned} 21(7) \\
6(2) \\
15(5)\end{aligned}$ & $\begin{array}{l}4 \text { to } 10 \\
0.5 \text { to } 4 \\
3 \text { to } 8\end{array}$ \\
\hline
\end{tabular}


Table 2 Defects found at screening by orthoptists that lead to referral in each birth year cohort

\begin{tabular}{|c|c|c|c|c|}
\hline \multirow[t]{2}{*}{ Defect } & \multicolumn{2}{|c|}{$1980(n=298)$} & \multicolumn{2}{|c|}{$1982(n=300)$} \\
\hline & $\begin{array}{l}\text { Total } \\
\text { No }\end{array}$ & $\begin{array}{l}\text { No of false } \\
\text { positives }\end{array}$ & $\begin{array}{l}\text { Total } \\
\text { No }\end{array}$ & $\begin{array}{l}\text { No of false } \\
\text { positives }\end{array}$ \\
\hline $\begin{array}{l}\text { Reduced vision in one eye } \\
\text { Reduced vision in both eyes } \\
\text { Convergent squint } \\
\text { Divergent squint } \\
\text { Reduced vision in one eye and convergent squint } \\
\text { Reduced vision in both eyes and convergent squint } \\
\text { Reduced vision in both eyes and divergent squint } \\
\text { Other }\end{array}$ & $\begin{array}{r}78 \\
59 \\
6 \\
1 \\
8 \\
4 \\
1 \\
2\end{array}$ & $\begin{array}{l}6 \\
1 \\
1 \\
0 \\
0 \\
0 \\
1 \\
1\end{array}$ & $\begin{array}{r}104 \\
57 \\
3 \\
1 \\
5 \\
4 \\
0 \\
2\end{array}$ & $\begin{array}{l}5 \\
3 \\
0 \\
0 \\
0 \\
0 \\
0\end{array}$ \\
\hline Total & 159 & 10 & 176 & 8 \\
\hline
\end{tabular}

Table 3 Defects that resulted in referral by school medical officers in each cohort by outcome of preschool vision screening

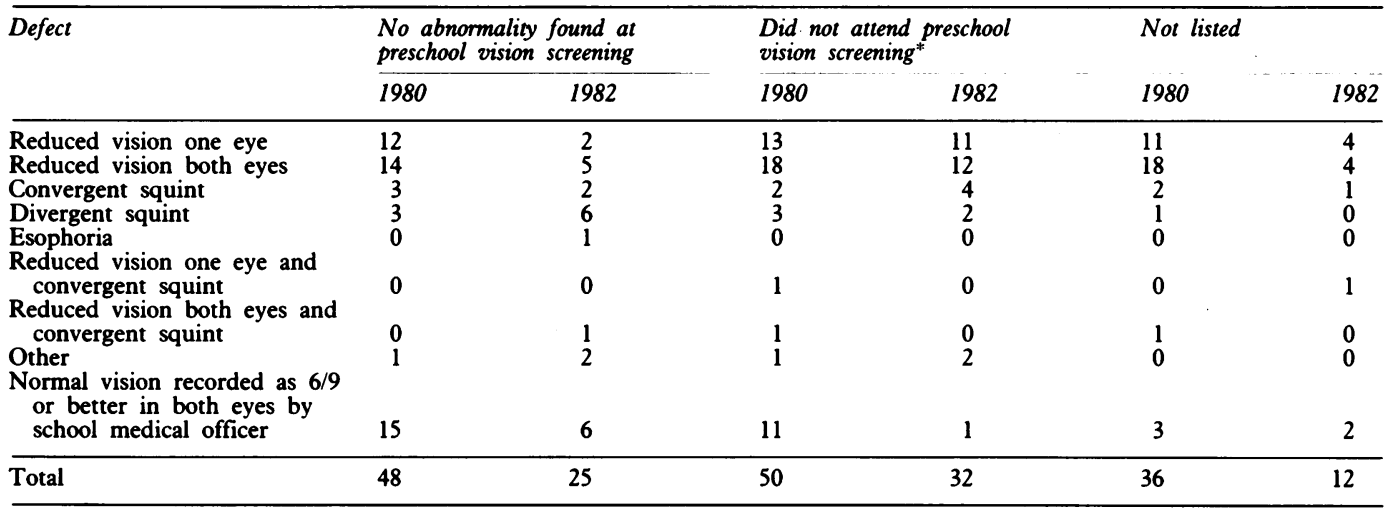

${ }^{*}$ Includes nine children whose preschool vision was unknown.

Table 4 Referrals after preschool vision testing and by school medical officers in each birth year cohort

\begin{tabular}{|c|c|c|c|c|}
\hline & \multicolumn{2}{|c|}{$1980(n=298)$} & \multicolumn{2}{|c|}{$1982(n=300)$} \\
\hline & No & $\begin{array}{l}\% \text { Of total } \\
\text { referred }\end{array}$ & No & $\begin{array}{l}\% \text { Of total } \\
\text { referred }\end{array}$ \\
\hline $\begin{array}{l}\text { Referred after preschool vision screening } \\
\text { True positive } \\
\text { Did not attend } \\
\text { False positive }\end{array}$ & $\begin{array}{r}143 \\
6 \\
10\end{array}$ & $\begin{array}{r}69 \cdot 1 \\
2.9 \\
4 \cdot 8\end{array}$ & $\begin{array}{r}151 \\
17 \\
8\end{array}$ & $\begin{array}{r}75 \cdot 1 \\
8 \cdot 5 \\
4 \cdot 0\end{array}$ \\
\hline Total & 159 & 76.9 & 176 & $67 \cdot 6$ \\
\hline $\begin{array}{l}\text { Referred by school medical officers } \\
\text { False negative preschool vision screening } \\
\text { False positive referral by school medical officers } \\
\text { Did not attend }\end{array}$ & $\begin{array}{r}21 \\
25 \\
2\end{array}$ & $\begin{array}{r}10 \cdot 1 \\
12 \cdot 1 \\
1.0\end{array}$ & $\begin{array}{r}12 \\
11 \\
2\end{array}$ & $\begin{array}{l}6 \cdot 0 \\
5 \cdot 5 \\
1\end{array}$ \\
\hline Total & 48 & $23 \cdot 2$ & 25 & $12 \cdot 5$ \\
\hline Total referred & 207 & 100 & 201 & 100 \\
\hline
\end{tabular}

Only 73 of them had been passed as normal at preschool vision screening, and 21 would have passed as normal by preschool vision screening referral criteria (they had 6/9 vision or better in either eye with no deviation on cover testing). The reasons for their referral was not apparent. Fifty two children, therefore, had potentially false negative diagnoses on preschool vision screening, and 33 were found to have defects.

The number of defects detected by school medical officers for all children born in 1980 and 1982 are listed in table 3 including the findings for those who did not attend for preschool vision screening and for those who were not listed and consequently not invited to preschool vision screening. A large number of divergent squints was detected by the school medical officers, all of which were false positives. The prevalence of defects among the non-attenders is similar to that among the attenders suggesting that there was no significant attendance bias in either direction. The number of unlisted chil- dren was much higher for the 1980 than the 1982 cohort (36 compared with 12).

\section{SENSITIVITY AND SPECIFICITY}

Table 4 summarises the true and false positive results of preschool vision screening, the false negatives for preschool vision screening (true positive referrals by school medical officers), and the false positive referrals by school medical officers. Also included is the number of children referred who failed to attend hospital (3.9\% for the 1980 , and $9.5 \%$ for the 1982 cohort); it is impossible to state whether they should have been referred.

Table 5 shows the sensitivity and specificity calculations for each cohort. The number of true negative results must be estimated from the attendance rate of the sample, and consequently a range is given that includes the $95 \%$ confidence interval (CI) around the sample estimate.

Table 6 shows the sensitivity, specificity, and 
Table 5 Calculation of sensitivity, specificity, and predictive value of preschool vision screening for each birth year cohort.

\begin{tabular}{|c|c|c|c|}
\hline \multirow[t]{2}{*}{ Screen result } & \multicolumn{2}{|c|}{ Referral outcome } & \multirow[t]{2}{*}{ Total } \\
\hline & Abnormal & Normal & \\
\hline $\begin{array}{l}1980 \text { Cohort } \\
\text { Positive } \\
\text { Negative }\end{array}$ & $\begin{array}{r}143 \\
21\end{array}$ & $\begin{array}{l}10 \\
2352 \text { to } 2778\end{array}$ & $\begin{array}{l}153 \\
2373 \text { to } 2799\end{array}$ \\
\hline Total & 164 & 2362 to 2788 & 2526 to 2952 \\
\hline $\begin{array}{l}1982 \text { Cohort } \\
\text { Positive } \\
\text { Negative }\end{array}$ & $\begin{array}{r}151 \\
12\end{array}$ & $\begin{array}{l}8 \\
2217 \cdot 5 \text { to } 2602 \cdot 5\end{array}$ & $\begin{array}{l}159 \\
2229 \cdot 5 \text { to } 2614 \cdot 5\end{array}$ \\
\hline Total & 163 & 2225.5 to 2610.5 & $2388 \cdot 5$ to $2773 \cdot 5$ \\
\hline
\end{tabular}

Table 6 Sensitivity, specificity, and predictive value (\%) for preschool vision screening for each birth year cohort

\begin{tabular}{lll}
\hline & 1980 & 1982 \\
\hline $\begin{array}{l}\text { Sensitivity } \\
\text { Specificity }\end{array}$ & 87.2 & 92.64 \\
$\begin{array}{l}\text { Predictive value: } \\
\text { Positive }\end{array}$ & 99.58 to 99.64 & 99.64 to 99.69 \\
Negative & 93.46 & 94.96 \\
\hline
\end{tabular}

predictive value of preschool vision screening for each cohort.

\section{Discussion}

This paper shows that in this setting, community orthoptists are efficient and accurate primary screening personnel.

There are many aspects to the full evaluation of a screening programme. These include measures of both process and outcome, as well as of cost effectiveness. This must take into account diverse marginal costs in addition to the costs of detecting and successfully treating a case, compared with the cost to the individual subject and community of failing to do so. Only measures of outcome of the performance of this screening programme are considered in this paper.

Children undergo numerous screening procedures for conditions that vary greatly in their severity and prevalence. Visual deficit has for a long time been regarded as a disability worthy of early detection and intervention, and is generally regarded as an important public health problem. ${ }^{10}$ There is little evidence that disability arising from unilateral amblyopia, be it strabismic or refractive, is of any importance except when there is blinding injury or disease in the seeing eye. There is also little evidence that children with profoundly amblyopic eyes can be successfully treated. This is exemplified by Ingram, who no longer advocates the early screening of children for visual deficit, and now seems to doubt the efficacy of treatment of children with more severe amblyopia. ${ }^{11-14}$ Other authors have reported some benefit from screening although not in properly controlled studies. ${ }^{15-17}$

For a disease to justify population screening, it must be shown that treatment is both tolerable and effective, at least in most cases. ${ }^{18}$ This aspect will be dealt with in greater detail elsewhere. The results of treatment are not remarkable, with a mean improvement of only one line on a Snellen chart for the whole group. The main determinant of successful outcome of treatment is the severity of amblyopia at the time of screening; age does not significantly influence outcome.
This study provides estimates of the outcome measures of the community orthoptists as primary screeners and the sensitivity, specificity, and predictive value are good, as they should be when the personnel have been specifically trained to detect visual abnormalities in small children. The performance of community orthoptists as primary screening personnel should be compared with results using health visitors as primary screeners and community based orthoptists as secondary screeners to whom children with possible abnormalities or who are thought to be at high risk are referred. Unfortunately there are no published studies with which an adequate comparison can be made. The figures for sensitivity, specificity, and predictive value would be hard to match in a two tier system, as would the much greater efficiency of a single tier system. We do not know the difference in cost between setting up and administering a dedicated primary preschool vision screening programme using community orthoptists and a two tier system.

One way of answering these questions would be to carry out a randomised trial of screening in a district in which a two tier primary programme is in operation. Children should be randomly selected to primary screening by a community orthoptist or to the existing health visitor based screening. The cost and logistics of the two approaches should be compared, as well as the measures of process and outcome. Alternatively, if it cannot be shown that health visitors are able to achieve a comparable level of performance, it is reasonable to conclude that community orthoptists are the most effective people to carry out the screening.

1 Hall DMB. Health for all children. Oxford: Oxford University Press, 1989:48-58.

2 Stewart-Brown SL, Haslum MN, Howlett B. Preschool vision screening: a service in need of rationalisation. Arch Dis Child 1988;63:356-9.

3 Kohler L, Stigmar G. Vision screening of 4 year old children. Acta Paediatr Scand 1973;62:17-27.

4 Oliver M, Nawratzki I. Screening of pre-school children for ocular abnormalities. Brf Ophthalmol 1971;55:462-6.

5 Cameron J, Cameron M. Visual screening of preschool children. $B M \mathcal{F}$ 1978; ii: 1693-4.

6 Maclennan A, Harker P. Mobile orthoptic service for primary screening of visual disorders in young children. $B M \mathcal{F} 1979$; i:994-5.

7 Hall S, Pugh A, Hall D. Vision screening in the under-5's. BMf̈ 1982;285:1096-8.

8 Bearsdell R. Orthoptic visual screening at 3.5 years by Huntingdon Health Authority. British Orthoptic fournal 1989;46:7-13.

9 Edwards R, Whitelaw A, Abbot A. Orthoptists as pre-school screeners: a 2 year study. British Orthoptic foumal 1989;46: 14-19.

10 Oberbeck TG. Vision screening of preschool and school-age children. Fournal of Ophthalmic Nursing Technology 1988;7: 96-99.

11 Ingram R. Amblyopia; the need for a new approach. $\mathrm{Br}$ f Ophthalmol 1979;63:236-7.

12 Ingram R. The possibility of preventing amblyopia. Lancet 1980;i:585-7.

13 Ingram RM, Holland WW, Walker C, Wilson JM, Arnold $\mathrm{PE}$, Dally S. Screening for visual defects in preschool children. Brf Ophthalmol 1986;70:16-21.

14 Ingram RM. Review of children referred from the school vision screening programme in Kettering during 1976-8. $B M \mathcal{F}$ 1989;298:935-6.

15 Feldman W, Milner R, Sackett B, Gilbert S. Effects of preschool screening for vision and hearing on prevalence of vision and hearing problems 6-12 months later. Lancet 1980; ii:1014-6.

16 Kohler L, Stigmar G. Visual disorders in 7-year-old children with and without previous vision screening. Acta Paediatr Scand 1978;67:373-7.

17 Nordlow $W$, Joachimsson $S$. The incidence and results of treatment of reduced visual acuity due to refractive errors in four year old children in a Swedish population. Acta

18 Wilson JMG, Junger G. Principles and practice of screening for disease. Public health papers No 34. WHO: Geneva, 1968 .
distice of screening for 